\title{
Wireless RFID Networks for Real-Time Customer Relationship Management
}

\author{
Philipp Schloter ${ }^{1}$ and Hamid Aghajan ${ }^{2}$ \\ ${ }^{1}$ Detecon, Inc., San Mateo, CA 94402 \\ pschloterastanfordalumni.org \\ ${ }^{2}$ Wireless Sensor Networks Lab, Department of Electrical Engineering, \\ Stanford University, Stanford, CA 94305 \\ aghajandstanford.edu
}

\begin{abstract}
A new system for real-time customer relationship management is proposed. The system is based on deploying a network of RFID readers throughout an environment. Information about the presence or lingering of participating customers at different times of day is collected providing valuable marketing information for better service provision. The implementation of the proposed system includes a database management program and an intuitive user interface allowing real-time access to the data acquired by the network.
\end{abstract}

\section{Introduction}

Increased competition is forcing retailers to leverage all information available in order to optimize their operations and improve their bottom-line. As part of this effort, understanding customers and managing the customer relationship is critical. As a result, the market for customer relationship management (CRM) [7, 8] software has exploded over the last decade - The Economist estimated the market for customer relationship management software alone at over \$11B for 2004 [1]. The next wave of growth in this area is already on the horizon - RT-CRM (real-time customer relationship management) [9]. RT-CRM will enable interacting with customers effectively around the clock. A major component of such an approach is tracking customer behaviour on retail and exhibition floors, which enables managers to optimize floor layout, and plan promotions and other marketing efforts accordingly. While existing prototypes are extremely expensive and complicated to deploy, our new system can offer similar capabilities at much lower cost. With the advent of decentralized wireless sensor networks [2], the cost of deploying sensing technologies will go down significantly. In this paper, we describe a novel prototype system of a wireless sensor network-based RT-CRM system, employing RFID [5] for sensing. The designed infrastructure lays the foundation for future research in the area of wireless sensor networks and next-generation CRM. By cutting the total system cost by at least an estimated factor of ten, wireless sensor networks will bring RT-CRM to the masses.

Existing system designs require a complete redesign of the floor space and hence are extremely expensive to deploy, limiting applicability to prototype environments or very large scale operations. An example for such a prototype environment is the Metro future store [3]. Metro designed a new store to demonstrate and test upcoming tech- 
nologies relevant to retailers. An RFID-based shelf and shopping cart content tracking system was deployed at the Metro future store. RFID allows Metro to track its entire inventory electronically and enables customers to self check-out without a cashier.

Harrah's casino is an example of a very large scale non-prototype RT-CRM operation. Harrah's Entertainment casinos [6] introduced a customer loyalty card. Patrons need to insert their loyalty card into the casino's slot machines in order to play. Harrah's has over 36,000 such slot machines. The loyalty card uniquely identifies the patron and enables Harrah's to visualize the casino floor in real-time by attributes such as age, average spent, game or drink preferences. Harrah's can then optimize its casino floor [4] and even run custom-tailored promotions, such as offering the player her favorite drink, keeping her happy and playing - all in real-time.

The high cost of deploying and maintaining the type of systems as deployed by Harrah's or Metro limits the use of such real-time CRM technology to a select few, very large players in industry. While this type of technology can greatly improve revenue, it is prohibitively expensive. It requires a large data warehouse with specialized software and a complete redesign of the floor space to install the necessary electronics. Further, current technology cannot track customer movements on the floor unless customers insert or swipe a loyalty membership card at all places as they move, e.g. at slot machines. These constraints further limit the applicability of RT-CRM.

\section{Approach}

We propose a new low-cost RT-CRM system based on a wireless sensor network. In contrast to previous systems, our system is significantly less expensive to deploy. It requires neither extensive remodeling of the floor space nor computer specialists to deploy and operate the system. The system is almost completely self-configuring, allows tracking of customer movements even without swiping a loyalty card, and can be deployed without any redesign of the floor space. The system is applicable in a variety of environments, including retail, exhibitions and museums. We believe that our design will make RT-CRM a reality even for small- and medium-sized businesses.

\subsection{Infrastructure}

Our infrastructure consists of six components:

1. A set of wireless sensors, equipped with RFID readers, which collect readings from RFID-based loyalty cards.

2. An aggregator mote that accumulates the data from the sensors.

3. An aggregation server that receives the data from the aggregator mote and stores it into a database.

4. A database server that runs databases for a) sensor data, b) customer information and c) system settings. It also provides a hook to other back-end systems such as inventory or cash register management systems.

5. A data processing entity that mines the data in the database. The web server triggers this data processor.

6. A web server that hosts a web-based system administration interface and also visualizes the data results received from the data processor.

Graphically, the systems can be described as in Fig. 1. 


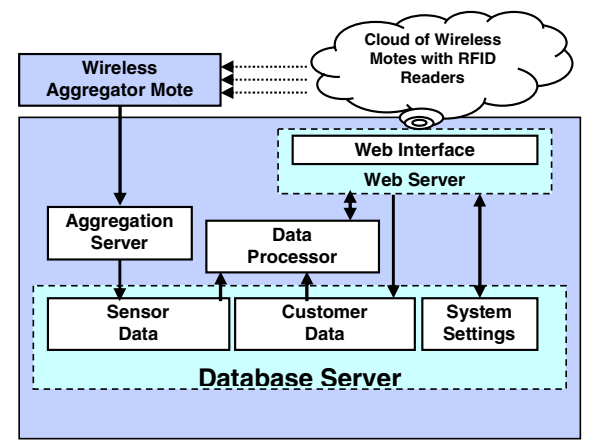

Fig. 1. Schematic overview of system infrastructure. Arrows indicate direction of data flow.

\section{Implementation}

In contrast to existing designs, our design does not require an entire redesign or upgrade of the floor space. In this section, we explain the deployment process in a typical retail environment.

Instead of having to redesign the entire store to incorporate RT-CRM technology, a store manager simply walks through the store and places wireless sensor motes on the different shelves to track customers. This store "walk-through" is a one-time process. At the entrance, RFID-enabled loyalty cards are distributed to customers.

These cards are just the size of a credit card and carry a unique customer identifier that links to a customer entry in a database (they might also carry part or all of the actual customer data). The cards are wireless, so as a customer passes by a wireless sensor mote, the customer is automatically tracked. During checkout, an electronic cashier tracks the customer again and the information about the purchase is linked to the customer database entry. The store manager can add additional motes at anytime, increasing precision on the fly as required and reducing the initial investment.

The store manager administers the system through a web-site. After having distributed the motes throughout the store, the store manager can load a map of the store via the web interface and graphically align the motes on the map (see Fig. 2(a)). This way the store manager knows exactly what store areas a set of customers visited.

\subsection{Operation and Analysis}

In this section, we describe our system's easy-to-use maintenance and analysis web interface. Products can be added at any time and the corresponding sensors are added to the map. One could employ a system extension that even automatically positions the sensors on the floor map, e.g. via RSSI-based triangulation or other localization techniques. Such a feature would especially help for large deployments with many sensors. Since products can be labeled and added at any time, managers can grow the system organically. For example, initially only aisles might get distinguished, but then, as additional precision is required and budget allows, additional sensors are added, e.g. to distinguish different sections of an aisles or even individual shelves. 


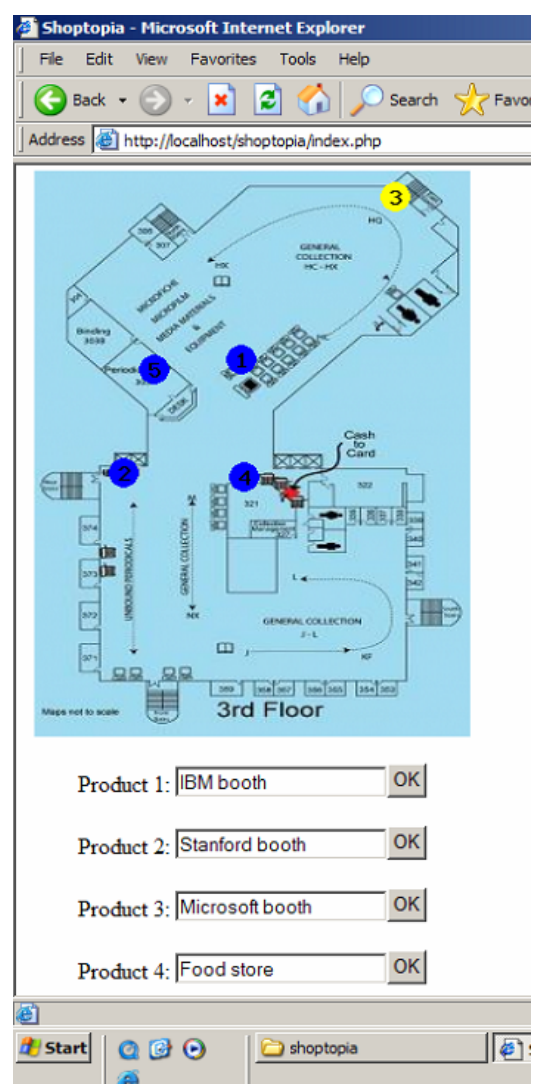

(a)

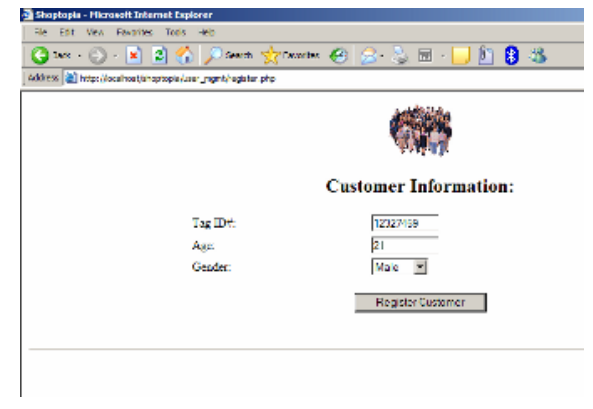

(b)

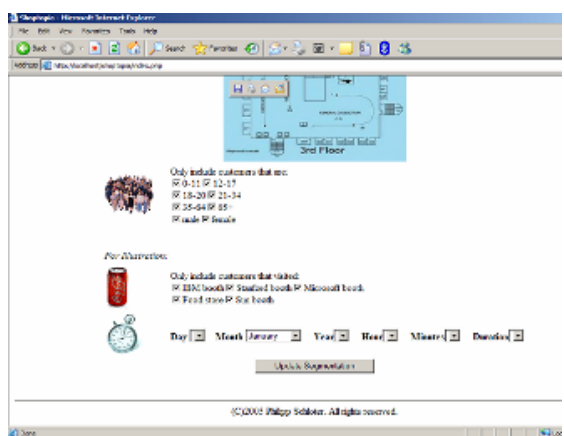

(c)

Fig. 2. Web interface (a) Arranging and labeling the sensors, (b) Entering customer information, (c) Example list of attributes for segmentation

In the prototype version, users sign up via the web interface. A stand-alone registration console is also possible. The current system requires users to enter their loyalty card number and their age and gender manually (see Fig. 2(b)) as the CRM data statistics. This step can be eliminated in a real deployment by enabling an RFID-based recognition of the card at the store front. This data is stored in the customer database and is used for segmentation. Clearly, the card number could also link to other customer information systems with more customer detail, e.g. ZIP code, level of education or customer's purchase history. Such information systems are already employed in conjunction with store loyalty cards used for recording purchases.

The collected data is visualized via "heat maps." The "\# of visitors" view indicates the volume of customers. Red means the sensor's visitor volume is in the top $25 \%$ percentile of all the sensors volumes. Blue means the sensor's visitor volume is in the bottom $25 \%$ percentile of sensors' volumes. Yellow represents the $25 \%-75 \%$ percentile, i.e. an average volume of visitors. 

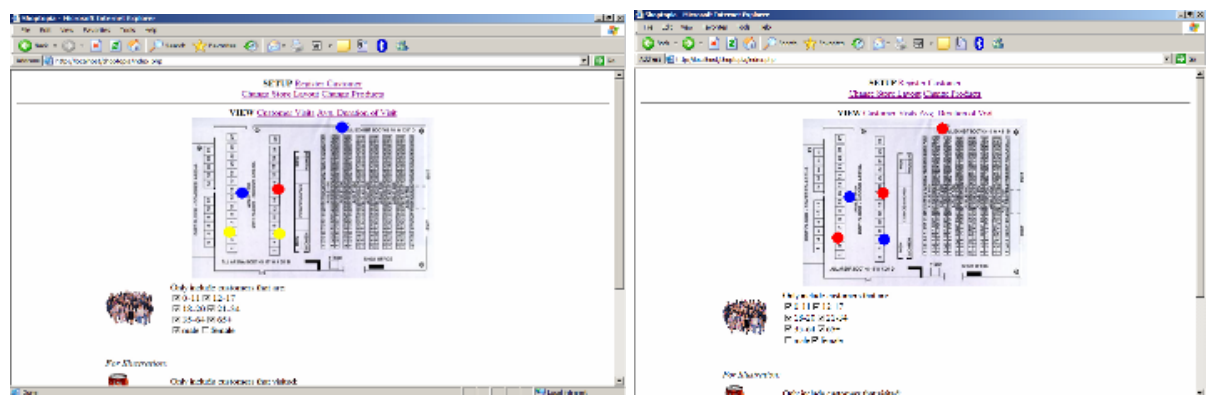

Fig. 3. Web interface - Example of difference in female and male in-store behaviours

Visitors can also be segmented by attributes such as age group, gender, products or booth visited. The data processing can be limited to a certain time span, e.g. early afternoon or between 1 and 2pm (see Fig. 2(c)). In addition, the average duration spent at a location is visualized. The average duration indicates how long customers take before they decide to purchase. The radius of each coloured circle indicates the range of the sensor. Red indicates long average duration, yellow indicates average duration $(25 \%-$ $75 \%$ percentile) and blue indicates low average duration. Other visualizations are also feasible. For example, one could visualize the flow of customers between different locations. The mentioned segmentation functionally allows for example to illustrate how the in-store behaviour of female and male shoppers differs (see Fig. 3).

\section{Data-Driven Decisions}

Based on the visualizations, managers can quickly identify problem areas and deduce possible actions to improve performance, i.e. customer satisfaction and/or revenue.

For example, let's say the number of customers that visited a location is low and the percentage of those customers who bought the product carried at the location is low. No matter how much time customers spent at the location, it is likely that the target customer for the product simply rarely finds the product in the store. A manager should consider making the product more visible. For example, he could add signs to help direct customers or, if there is still no demand whatsoever for the product, the manager might decide to drop the product entirely.

If a lot of customers visited a location, spent a lot of time at the location, but did not buy after all, there might be too little information for the customers to decide on a purchase immediately. There could be many reasons. The store might carry too many similar products, there might be too little product information available for customers to form a decision, or it might just be the nature of the offering that purchase decisions take time. The manager should look into adding product information and/or investigate if adding sales staff to answer customer questions is feasible. Alternatively, there might also be problems with a product's packaging. This information could be valuable for the product management of the supplying company.

If a lot of customers visited a location, spent little time and bought little, it is likely that this passage is just a "walk-through," leading customers to other products. The manager might consider swapping out the product located here with a product that is 
more relevant to the passing-by customers. This way the store could benefit from increased impulse purchases.

Many other scenarios can be deducted from the high-level visualizations provided by the system. Our system could even automatically detect certain data patterns and provide an according list of recommendations to the manager. The manager then could implement the recommended changes she thinks are most feasible. Finally, our system, linked to a cash register system, could measure the overall revenue impact and ROI of the implemented changes.

\section{Cost Comparison}

In this section, we will estimate the cost of deploying our wireless sensor networkbased system and compare it with traditional systems. Since every deployment is different, it is challenging to provide an estimate for all cases. However, the following analysis should at least indicate the magnitude of potential cost savings.

Table 1. The major cost components in traditional systems and in the proposed technique.

\begin{tabular}{|c|c|c|}
\hline & Traditional & Proposed System \\
\hline Software & $\begin{array}{l}\text { Highly specialized, } \\
\text { costly software from } \\
\text { multiple vendors - } \\
\text { rarely web-based / } \\
\text { rarely hosted service } \\
\text { model. }\end{array}$ & $\begin{array}{l}\text { Low-cost, single } \\
\text { vendor and possibil- } \\
\text { ity to offer as hosted } \\
\text { service with little } \\
\text { up-front cost. }\end{array}$ \\
\hline Hardware & $\begin{array}{l}\text { Often times data } \\
\text { center; multiple } \\
\text { machines since } \\
\text { different vendors } \\
\text { might require differ- } \\
\text { ent platforms and } \\
\text { each application } \\
\text { might require a } \\
\text { dedicated machine } \\
\text { by itself. }\end{array}$ & $\begin{array}{l}\text { One PC (possibly on } \\
\text { remote-side) } \sim 1000 \\
\text { today } \\
\text { Est. } \$ 10 / \text { sensor } \\
\text { (declining as adop- } \\
\text { tion increases) } \\
\text { Est. } \$ 0.5 / \text { loyalty } \\
\text { card (declining as } \\
\text { adoption increases) }\end{array}$ \\
\hline Deployment & $\begin{array}{l}\text { Usually remodeling } \\
\text { of floor space re- } \\
\text { quired; swap out of } \\
\text { equipment (e.g. } \\
\text { store shelves or slot } \\
\text { machines), data } \\
\text { cables need to be } \\
\text { installed throughout } \\
\text { the floor space. }\end{array}$ & $\begin{array}{l}\text { Less than } 30 \text { min- } \\
\text { utes of initial train- } \\
\text { ing per manager } \\
\text { Est. } 30 \text { seconds } \\
\text { /sensor } \\
\text { No data cabling to } \\
\text { all aisles or shelves } \\
\text { required. }\end{array}$ \\
\hline Maintenance & $\begin{array}{l}\text { Requires staff of IT } \\
\text { experts. }\end{array}$ & $\begin{array}{l}\text { Web-based, man- } \\
\text { aged directly by } \\
\text { manager. Products } \\
\text { and sensors can be } \\
\text { added any time. }\end{array}$ \\
\hline
\end{tabular}


The cost of a system can generally be divided into four areas: software, hardware, deployment, and maintenance. In Table 1, we list some of the key cost drivers in each area for traditional systems and for our system. Due to its high cost up to now, computer systems were only used by few entities in measuring and analyzing customer behaviour on the floor.

Traditionally, external or in-house consultants are hired sporadically to observe customers on the floor. By taking extensive notes, these consultants would analyze customer movement patterns, preferences and other behaviour to develop a set of recommendations on how to adjust the store layout. Hiring a consultant for a few hours can easily cost thousands of dollars and this traditional approach does not allow for the continuous tracking of trends. Continuous tracking is essential in a world of cyclical buying patterns, ever-changing product lineups, changing customer preferences and fast-moving competition. Considering the low margins in the retail business, a revenue increase due to better customer behaviour data by even a few cents per unit can yield significant additional profit. A mean of continuously tracking customer behaviour such as the proposed system can have a big business impact.

In Table 2, we estimate the cost of a traditional system vs. our new system. Please note that this calculation is only an estimate and that each scenario is likely to be different. However, these numbers should give an idea of the magnitude of the cost difference between the two systems. The required investment for the new system should be lower by a factor of 10 or more in comparison to traditional systems. Maintenance costs should be lower by a factor of 20 with our new design. Note that the fixed cost of the proposed system is significantly lower.

By utilizing a hosted service model with sensor network motes, the system can organically grow, reducing fixed costs and making it especially attractive to smaller stores. Clearly, the reduced cost will bring RT-CRM type applications to a broader audience. In addition, with the new system, businesses could start with a small deployment and add precision and sensors as needed, further lowering the required initial investment. Larger stores can benefit from the flexibility of the system by rotating the motes between different aisles, reducing the investment, while still producing an insightful view on customer behaviour.

Table 2. The costs are likely to be considerably less in the proposed system

\begin{tabular}{|l|l|l|}
\hline \multicolumn{1}{|c|}{ Traditional } & \multicolumn{1}{c|}{ Proposed System } \\
Hoftware and & $\sim \$ 50,000$ & $\sim \$ 1,500$ \\
\hline Sensors & NA & $\sim \$ 10,000$ \\
\hline $\begin{array}{l}\text { Remodelling of } \\
\text { shelves } \text { Cabling }\end{array}$ & $\sim \$ 100,000$ & NA \\
\hline $\begin{array}{l}\text { Deployment } \\
\text { Labour }\end{array}$ & $\sim \$ 50,000$ & $\sim \$ 1,000$ \\
\hline $\begin{array}{l}\text { Maintenance } \\
\text { Labour }\end{array}$ & $\sim \$ 100,000 /$ year & $\underline{\sim 5,000 / \text { year }}$ \\
\hline Total & $\underline{\sim \$ 200,000+\$ 100,000 / y r}$ & $\underline{\underline{\sim 12,500+\$ 5,000 / y r}}$ \\
\hline
\end{tabular}




\section{System Integration Components}

The first prototype system was implemented using a low-frequency RFID reader from Texas Instruments. The TI Passive RFID SDK kit was used for RFID reading. The server ran on MySQL and Apache on a laptop computer. Code was developed in various $\mathrm{C}$ derivatives as well as PHP. We are investigating several potential extensions to our initial prototype. Having the described infrastructure in place, new ideas and concepts can be quickly prototyped and tested. In particular, we have identified six key areas for extending the application:

1. Sensing: Includes long-range passive RFID technology, potentially aided by multiple reader antennas, simultaneous reading of very high volumes of RFID tags, and the automatic detection of possible intruders or hackers.

2. Communication: Includes finding the ideal trade-off point between aggregating data over a period of time at the mote sensor and the ability to have real-time information via high-frequency updates for different environments. Another area of concern is security, since the transmitted information might be of high interest for competitors.

3. Storage: Includes evaluation of the trade-off between only storing the required metrics for analysis, or storing all received data, which requires more storage. In addition, scalability and lifetime tests in real environments should be conducted.

4. Visualization: In this module the most relevant and actionable metrics are identified via conducting a user testing. In addition, real-time visualization and animation enhance the functionality of the system.

5. Analysis: Includes automatic detection of data patterns and events, and forming a list of appropriate recommendations. The automatic tracking of promotions and time series analysis in real-time enables another entire application.

6. Administration: Includes new ways of simplifying deployment and maintenance of the network. For example, automated localization of sensors upon deployment would eliminate the manual step of aligning the sensors with the floor map and, as a result, would greatly reduce the network setup time.

\section{Customer Privacy}

In order to facilitate adoption among customers of retail stores, the privacy concerns implied by the use of the tagged loyalty cards need to be addressed.

To this end, participating customers can be assured that the collected data is solely used for statistical analysis and no personally identifiable information is used in the market analysis process. Use of loyalty cards in super markets and wholesale membership clubs has proven successful in retaining participants via offering discount incentives. The user can be given an option to opt out from the CRM system, but discount offers would provide adequate incentives for many to participate.

In other settings, tags could be installed on shopping carts instead of having customers carry them. While this approach may provide an alternative to addressing privacy concerns, the disadvantage in adopting such method would be that customer segmentation may not be readily possible. In order to understand the behaviour of various different customer segments, it is essential that the proposed CRM system can link information with customer profiles. 
Customers are willing to give up some privacy, if they gain something for it in turn. Client recognition service programs can provide a customized shopping experience. Customers gain by benefiting from customized services that are rendered to participants depending on the context and their stated preferences. Several casinos and membership-based recreation clubs have successfully deployed such customer service programs.

Finally, a single loyalty card that works across stores could be another option. Such a card can significantly improve service rendition to patrons. For example, the system could automatically guide the participating customers throughout a mall to the stores that carry their desired items.

\section{Conclusions}

The next wave of growth in customer relationship management is on the horizon - RTCRM. In the future, firms will track customer behaviour on retail and exhibition floors and react in real-time by altering business levers such as floor layout, promotions, product mix and advertising. While existing prototype systems are extremely expensive and complicated to deploy, the system we implemented offers similar capabilities at much lower cost. By cutting the total system cost by at least an estimated factor of 10, wireless sensor networks will bring RT-CRM to the masses. Our prototype system lays the foundation for a plethora of new projects and will help to open up new fields, bridging customer relationship management and wireless sensor networks.

\section{Acknowledgments}

We would like to thank the entire team at the Stanford Wireless Sensor Network Lab. We also would like to thank John Fogelsong and Texas Instruments for providing the RFID equipment.

\section{References}

[1] The Economist, March 2004 Edition, p. 95.

[2] I.F. Akyildiz, W. Su, Y. Sankarasubramaniam, and E. Cayirci. A Survey on Sensor Networks. IEEE Communication Magazine, August, 2002.

[3] The Metro Store of the Future. http://www.future-store.org/

[4] Compudigm Company Brochure, seePOWER ${ }^{\mathrm{TM}}$ V4 Gaming In Action

[5] K. Finkenzeller. RFID Handbook. John Wiley \& Sons. 1999.

[6] David O. Becker. Gambling on customers. The McKinsey Quarterly, 2003 Number 2.

[7] C.K. Prahalad, Patrica B. Ramaswamy, Jon R. Katzenbach, Chris Lederer, Sam Hill. Harvard Business Review on Customer Relationship Management. Harvard Business School Press, January 15, 2002.

[8] P. Child, R. Dennis, T. Gokey, T. McGuire, M. Sherman, and M. Singer. Can marketing regain the personal touch? The McKinsey Quarterly, 1995 Number 3.

[9] R. Sedgewick. Real-time CRM: a competitive advantage today, a competitive imperative tomorrow? Customer Interaction Solution, Volume: 22 Issue: 8 Page: 50(3), February 1, 2004. 